\title{
THE VICTORIAN MENTAL SCIENCES
}

\author{
By Suzy Anger
}

IN A 1990 REVIEW OF Jenny Bourne Taylor's In the Secret Theatre of Home: Wilkie Collins, Sensation Narrative, and Nineteenth-Century Psychology (1988), Lawrence Rothfield commented that the book explores what "until recently might have seemed a bizarrely specialized cultural context and an equally obscure literary phenomenon" (97). Rothfield argued that Taylor's study was representative of the recent move to new historicist methodologies, which made contexts and authors once considered to be historical footnotes important to scholarship. Prior to that shift, "[n]ineteenth-century English psychology, a mishmash of scientifically dubious theories and practices such as phrenology, physiognomy, moral management, and mesmerism, hardly seemed key to understanding the broad cultural issues of concern as traditionally construed in Victorian studies" (97). Strikingly, now some twenty-five years later, knowledge of nineteenth-century psychology seems essential to the field. Presses, alert to that shift, have republished out-of-print literary studies that explored Victorian literature in relation to psychology in the years preceding the current surge of interest in the subject. (Faas's 1989 Retreat into the Mind: Victorian Poetry and the Rise of Psychiatry was reissued by Princeton University Press in a 2016 hardcover edition. Kearns's 1987 Metaphors of Mind in Fiction and Psychology was reissued in 2014 by the University of Kentucky Press.) Judging by the number of publications in the area, as well as by titles on the programs of recent conferences, the sciences of the mind have become one of the central topics in Victorian studies.

Why has nineteenth-century psychology come to be regarded as a crucial context for understanding Victorian literature and culture? As Rothfield noted, new historicist methods played a large role in changing the contours of literary studies, as did the increasing emphasis on interdisciplinarity in Victorian studies. Some of the changes in the field of Victorian studies might be explained by the influence of particular distinguished studies, such as those on the intersections of nineteenth-century literature and science by Gillian Beer and George Levine. It has, of course, often been suggested that the interpretive perspectives we construct are largely responsible for the Victorian period we now analyze. Yet, to temper that view, developments in the sciences of the mind in the nineteenth century were so enormously influential that examination of them is crucial to an adequate understanding of the period. The delay in recognizing the centrality of psychology to Victorian culture might be accounted for, at least partially, by the unquestioned acceptance of a particular framework of psychological concepts. That framework was so thoroughly taken for granted as to seem inevitable. Only subjects that seemed quaint and outdated, like mesmerism or phrenology, were regarded as 
particularly characteristic of Victorian psychology, and other forms of psychological language were overlooked.

In the nineteenth-century, "psychology" first came to be used in Britain to describe the subject matter that we now understand by the term, and late in the period "Psychology" became a discipline, with its own journals and professional organizations. In the later part of the century, the first psychological laboratories were established and the first textbooks in psychology published. Scientific, physicalist theories of mind challenged religious views on personal identity (nothing new, but more widely accepted and more widely discussed in the culture than in previous periods). Physiological research on reflexes, the nervous system, sensation, and brain pathology, and, later, on neuroanatomy and the specialized functions of cerebral regions informed psychology and the emerging discipline of psychiatry. Evolutionary and hereditary theories of mind were developed in the second half of the period. Forensic psychology entered into criminal trials, raising questions about the attribution of responsibility. We know that novelists such as George Eliot had close personal connections to key figures (in Eliot's case, George Henry Lewes and Herbert Spencer) in the emerging discipline, and that they incorporated ideas from scientific writing on the mind into their literary works. Thomas Hardy read widely in the psychological literature, recording his readings in his notebooks and bringing the ideas he encountered into play in his fiction. Philosopher Andrew Seth began an 1893 article on "The New Psychology" in the Contemporary Review with the assertion that "all who take an intelligent interest in the movement of contemporary thought ... are aware of the great activity which has been shown of late years in the department of psychology" (555). Literate Victorians, as revealed by the number of pieces in popular periodicals, read and wrote widely on subjects connected to the mental sciences.

Developments in the sciences of the mind in the nineteenth century transformed our notions of what it is to be human. Some of the terrain explored in the Victorian science of mind is now regarded as hopelessly misguided: theories of degeneration, theories of hysteria, evolutionary psychology in service of scientific racism, among other topics. Still, those ideas were popularized and permeated the culture, meaning that critical analysis of them is essential both to our understanding of the Victorian period and to our understanding of the ways in which those ideas may continue to resonate in current thought. As recent theorists of science have demonstrated, scientific knowledge always has a diachronic aspect. Moreover, the boundaries between science and pseudoscience are often redrawn over time. If the sciences of phrenology and mesmerism were discredited already by the mid-nineteenth century, those theories continued to influence literary texts throughout that century and to be important to the development of ideas - brain localization, automatisms - that remain central to neuroscience and psychology today.

Current historical and literary work has turned to consideration of the ways in which mentality was conceived of and represented in the Victorian period, and the ways in which those views on mentality altered understandings of the self. As suggested above, what might have once seemed a narrow area of concern to twentieth-century scholars was in fact crucially significant, leaving its marks on most Victorian texts and encompassing a range of topics, including the grounding of psychology in biology, theories on the relation between brain and mind, constructions of psychopathology, studies of altered mental states (dreaming, hallucination), theories of the unconscious, re-imaginings of the role of conscious volition in behavior, the study of comparative psychology (animal minds), the study of the criminal 
mind, and the relations between the supernatural and new understandings of the mind, to name just a few. The Victorian sciences of the mind, along with the recent critical work on them, extend from psychology into medicine, philosophy, legal studies, the occult, and beyond, with recent contributions to the critical and historical literature too numerous to cover in one review article.

In outlining the research, I have space here to focus on a handful of fairly recent monographs (leaving aside some important articles), but will point as well to earlier books that have been foundational to subsequent work. Several of the books I discuss are historical studies, from fields such as cultural geography and sociology, and several are literary studies. Together they give a sense of the diversity of issues that have engaged scholars examining the Victorian sciences of the mind. I will not consider studies of insanity and the asylum, an extensive body of work that would require a review article of its own, nor will I comment upon recent work that aims to bring current cognitive approaches to bear on Victorian literature.

\section{History, Sociology, and Cultural Geography}

HISTORIANS OF VICTORIAN PSYCHOLOGY have attended to the local, historical construction of psychological concepts, tracking changes in the meaning of psychological terms, and considering the social and cultural contexts of psychological ideas. Of the many fine works in the history of science that have extended our knowledge and influenced later work, I would single out Kurt Danziger's Naming the Mind (1997); Anne Harrington's Medicine, Mind, and the Double Brain: A Study in Nineteenth-Century Thought (1987); Edwin Clarke's and L. S. Jacyna's Nineteenth-Century Origins of Neuroscientific Concepts (1987); Robert M. Young's Mind, Brain, and Adaption (1970); Robert Richards's Darwin and the Emergence of Evolutionary Theories of Mind and Behavior (1989), and Alison Winter's Mesmerized: Powers of Mind in Victorian Britain (1998).

I consider first a recent study, Free Will and the Human Sciences in Britain, 18701910 (2013), written by the historian of psychology Roger Smith, author of Inhibition: History and Meaning in the Sciences of Mind and Brain (1992), Trial by Medicine: Insanity and Responsibility in Victorian Trials (1981), and a number of influential articles in the field. Smith's newest study is a masterful, capacious, and richly detailed account of late nineteenth-century British intellectual debates on free will versus determinism (hence volition and agency) across the human sciences in the context of a culture increasingly receptive to a naturalist worldview. Drawing on his commanding knowledge of Victorian discussions of the mind, Smith's analysis demonstrates the pervasiveness and crucial importance of those debates to the culture. The second chapter, "Physiology and the Mind," focuses on theories of automatism arising from work in physiology, such as studies of reflex action, which link mental and physical processes and seem to reduce will to a bodily process. Such views gave rise to anxieties about unconscious behaviour and the potentially illusory nature of volition (topics that were important to much of Smith's earlier research as well). Materialist views were countered by work that sought to retain metaphysical notions of the will, such as that of physiologist William Carpenter, who constructed a faculty of the "Will" as distinct from and directing automatic processes. The chapter also considers the extension of the reflex model into evolutionary conceptions of mind, which situated automatisms at the primitive levels, beneath the volitional and rational levels of the brain 
that were understood as having developed later in evolutionary history. These ideas entered pervasively into popular discussion, particularly in relation to morality. The third chapter, "Shaping the Science of Psychology" focuses on the emergence of psychology "as an area of knowledge" (35) with competing theories, diverging methodologies, and debates over what counts as psychological language. Subsequent chapters examine arguments on mental activity in relation to freedom of the will, theories of heredity, debates on causation and mental activity, and the psychology of attention. The book recruits a remarkable range of primary materials to make its case, while also pointing to the legacy of nineteenth-century British thought for current discussions. Smith ultimately discovers in the writers he examines a commitment (that Smith himself endorses) to the efficaciousness of the will as being essential for human value and life. The book's emphasis on the human sciences means that it largely (aside from some scattered but interesting references) omits discussion of literary texts, where concerns about automatism and volition were equally important, leaving literary critics work yet to do.

Sociologist Joel P. Eigen's Unconscious Crime: Mental Absence and Criminal Responsibility (2003), a study straddling the history of psychology and legal history, examines one specific area in which concerns over volition, automatism, and morality shaped society: the mid-nineteenth-century courtroom. Eigen focuses on criminal proceedings, legal defences, and verdicts in trials (1843-76) in which criminal acts were said to have been performed while the perpetrator was in an altered state (that is, while sleepwalking, inhabiting an alternative personality - what was termed double consciousness - in a state of automatism associated with epilepsy, or while dreaming). The study takes these questions as its starting points: "When and where did ideas of splitting, of multiplicity, of fugue states evolve and how have common-law courts reacted to a defence of 'non-responsibility' based not on insanity but on the curious state of being missing at the time of the crime?" (3). The primary source materials for the book are mid-nineteenth-century accounts of the proceedings of trials in London's Central Criminal Court (as it was re-named in 1834) published in the Old Bailey Sessions Papers. Eigen demonstrates that in the Victorian period, courtroom discussion shifted away from an emphasis on insanity as constructed by the 1843 M'Naghton Rules, relying on cognitive criteria (for instance, whether the defendant was able to distinguish between wrong and right), to questions of unconscious behaviour and voluntariness (apart from any ascription of sanity or insanity). Eigen shows (here the book shares ground with Roger Smith's earlier study Trial by Medicine [1981]) that changing conceptions of automatic behaviour posed new challenges to ideas about legal responsibility. Can an unconscious subject, or an alternate personality - the famous fictional example is Dr. Jekyll and Mr. Hyde (1886) - be guilty of committing a crime? "Ultimately," Eigen writes, "the Old Bailey was asked to decide the criminal responsibility of a defendant who failed to rise to the law's conception of the Person. . . . Amnesia, absence, sleepwalking, possession, and 'automatic fits' would challenge fundamental Western beliefs that consciousness linked thought to act, and hence responsibility to assault. Medical writings might speculate on the possibility of automatic behavior, but only the courts could exonerate an automaton" (14).

Eigen shows that medical and legal practitioners - but also lay people - worked together to bring new medico-psychological conceptions into the courtroom. In an 1876 trial, Elizabeth Carr was charged with chopping off the hand of her infant - which led to the child's death. However, the new ideas on the mind had been so widely discussed in the general culture that the jury returned a verdict of their own making of "not guilty on the ground of 
unconsciousness" (10), the first time that special verdict was ever recorded. The book closely examines cases made, often unsuccessfully, for non-responsibility in a number of fascinating legal trials worthy of inclusion in a Wilkie Collins novel: the case of the nursemaid charged with attempting, in a somnambulistic state, to slash the throat of the child in her care; the case of the lodger who murdered her landlady in a state of mental "absence" brought on by the irregularity of her menstrual flow; the father who dashed his son against the wall while dreaming that he was fending off a wild beast. Central to Eigen's analysis is his claim that the trials demonstrate that the conception of "the person as a unitary being was nearing fatal rupture" (168). (The argument in that way connects to Ian Hacking's examination of multiple personality disorder and its emergence as a diagnostic category in the last decades of the nineteenth-century in Rewriting the Soul: Multiple Personality and the Sciences of Memory [1995]). Eigen also argues that the trials he studies reveal new ideas about the unconscious in the process of formation: the unconscious is re-conceived - pre-Freud - not as a storehouse of sometimes forgotten or inaccessible knowledge, but instead as the receptacle of unexpressed "resentments and hostilities" (34).

The Proceeding of the Old Bailey (1674-1913) have been digitized and are now searchable online: http://www.oldbaileyonline.org/. I was interested to find a case as far back as 1784 in which a judge, wonderfully named Baron Eyre, says of the defendant in his instructions to the jury: "Indeed he is either guilty of the crime of wilful murder, or he is a mere machine" ("William Walker," 21 Apr. 1784, Case 388). But that trial invoking automatism stands alone, whereas by the mid-nineteenth-century, it is striking how many defendants, particularly petty thieves and pickpockets, claimed that they had been "unconscious" of carrying out whatever act they were charged with doing. That the accused themselves (perhaps on the advice of their legal counsel) used automatism as a defense supports Eigen's contention that ideas concerning unconscious behaviour, disseminated in the larger culture in such varied forms as popular accounts of mesmeric trances and philosophical debates on volition, strongly marked ideas of criminal responsibility in the period. Unconscious Crime has recently been followed up with Eigen's new study Mad-Doctors in the Dock: Defending the Diagnosis 1760-1913 (2016), which uses the Old Bailey Proceedings to examine the increasing presence of medical experts at trials and the appearance of the diagnosis of homicidal mania in the nineteenth-century.

Cultural geographer and historian Shane McCorristine's fine first monograph Spectres of the Self: Thinking about Ghosts and Ghost-Seeing in England, 1750-1920 (2010) examines responses to reports of spectral sightings, in the time period in which ghosts largely came to be construed as mental phenomena, evidence of a haunted mind rather than of an actual supernatural visitation. Extending earlier work by historians such as Janet Oppenheim (The Other World: Spiritualism and Psychical Research in England 1850-1914 [1985]) and Alex Owen (The Darkened Room [1989] and The Place of Enchantment [2004]) on nineteenthcentury supernaturalism, spiritualism, and psychical research in relation to the sciences of the mind, McCorristine provides wonderfully detailed consideration of psychological and scientific perspectives on ghost seeing in the nineteenth century. In The Female Thermometer: Eighteenth-Century Culture and the Invention of the Uncanny (1995), Terry Castle explored the shift to "the belief that ghost and spectres are only products of imagination, that they come from within the mind itself" (170). McCorristine builds on that thesis, turning sustained attention onto a wide range of primary texts and examining both specialist literature and popular writing: scientific and medical papers, philosophical texts, psychological treatises, 
and periodical articles. The interdisciplinary study gives almost equal weight to literary works as evidence for its claims. McCorristine discusses texts by Charles Dickens, Charlotte Bronte, Nathaniel Hawthorne, Samuel Taylor Coleridge, James Joyce, Margaret Oliphant, Arthur Machen, and others. Two chapters of the book focus on the Society for Psychical Research's experimental work on telepathy and crisis apparitions (sightings of people's ghosts at the moment of their deaths). As McCorristine traces the changing views on ghost seeing, he simultaneously tracks shifts in the emerging discipline of psychology, as the literature moves from an interest in dreams to evolutionary/degenerationist models of behavior and into discussions of psychopathology.

\section{Literary Criticism}

LITERARY SCHOLARS, EXAMINING THE interactions between science and literature, have demonstrated in recent years how developments in views on mentality, consciousness, behavior, and the self, such as those examined in the studies discussed above, influenced nineteenth-century literary works. Conversely, they have shown how Victorian literary texts played a role in shaping psychological ideas. The groundbreaking work in the area came, in good part, from Sally Shuttleworth and Jenny Bourne Taylor. In George Eliot and Nineteenth-Century Science (1984), Shuttleworth traces the role of physiological psychology in George Eliot's novels. Shuttleworth extends those interests in Charlotte Bronte and Victorian Psychology (1996), which, taking a Foucauldian perspective, considers Bronte's fiction in the context of early to mid-nineteenth century writing on phrenology, nervous disease, and self-control. Taylor's In the Secret Theatre of Home demonstrates that Wilkie Collins's fiction draws upon a wide range of nineteenth-century psychological theory. Shuttleworth's and Taylor's Embodied Selves: An Anthology of Psychological Texts 18301890 (1998), with its lucid introductions, made primary material that had been largely forgotten central to Victorian literary studies. The excerpts included in the anthology have influenced the shape that Victorian literature and psychology studies have taken, meaning that other areas of psychological concern, for instance, the study of non-human animal minds, aesthetic psychology, and the psychology of attention have as yet received little attention in literary studies. Work on degeneration, such as Daniel Pick's Faces of Degeneration (1993) and William Greenslade's Degeneration, Culture, and the Novel (1994) brought increased attention to late Victorian evolutionary psychology and heredity theory in connection to nineteenth-century literary representation. Rick Rylance's Victorian Psychology and British Culture, 1850-1880 (2000) provides a detailed examination of the psychological literature (monographs and periodicals), organizing the debates into discourses on the soul, philosophy, physiology, and medicine. Rylance also closely considers the psychological writing of Alexander Bain, Herbert Spencer, and G. H. Lewes. Subsequent scholarship in the area has addressed increasingly more specific concerns within the debates. Several monographs have been devoted to the relations between Victorian psychology and particular authors, for example, Michael Davis's George Eliot and Nineteenth-Century Psychology (2006) and Suzanne Keen's Thomas Hardy's Brains: Psychology, Neurology, and Hardy's Imagination (2014). Jill Matus's Shock, Memory, and the Unconscious (2009) traces a pre-Freudian theory of trauma through Victorian psychology, physiology, medical, and literary texts, showing how Victorian conceptions of mental shock provide a genealogy for the development of later notions of trauma and the unconscious. Nicholas Dames's Physiology of the Novel (2007) 
examines mid-Victorian theories of reading grounded in nineteenth-century psychology and physiology. Anna Neill in Primitive Minds: Evolution and Spiritual Experience in the Victorian Novel (2013) examines the representation of dreamy states of mind (drawing on neurologist John Hughlings Jackson's discussions of epilepsy), such as double consciousness, déjà vu episodes, and trances in relation to depictions of "spiritual" experiences and evolutionary psychology.

Shuttleworth's most recent contribution to the field, The Mind of the Child (2010), examines nineteenth-century constructions of children's mental development. Bringing into play such varied genres as psychological and psychiatric writing, popular periodical articles, newly founded journals on childhood, treatises on child education, and autobiographies, Shuttleworth explores changing perspectives on the minds of children. Most important, she argues that the developing psychological and psychiatric literature drew heavily on literary representations of children, and that, moreover, Victorian fiction has been at least as significant in shaping our ideas of the child's mind as have been scientific and medical texts. The study is dense and comprehensive, following multiple lines of inquiry in connection with the Victorian novel. The first section of the book investigates changing views of childhood insanity, looking at theories of heredity as well as theories advancing the view that childhood cognitive and emotional disorders are the result of inadequate rearing. Shuttleworth also examines medical writing that contended that childhood insanity could develop in utero. The second part of the book focuses on children's education, and demonstrates that work on the harmful effects of over-pressure in education, authored by prominent psychiatrists and physicians such as James Crichton Brown and Robert Brudenell Carter, draw on Dickens's representations of brain forcing in Dombey and Son (1848). This is one of many moments in the study where Shuttleworth establishes specific links between literary depictions and subsequent theories in scientific work on child development. "Literary texts did not simply supply material for medical case studies," Shuttleworth writes. "[T]hey also helped frame the questions and categories of an emerging scientific field" (362).

The third part of the book examines post-Darwinian child psychology, focussing on evolutionary models of mind, the rise of developmental psychology, experiments on infant behavior, and pre-Freudian views of childhood sexuality. In a final section, Shuttleworth considers fin de siècle constructions of the child. A fine reading of Jude the Obscure (1895) considers Hardy's representation of the morbid, over-sensitive child - Little Father Time in the contexts of theories of degeneration, psychiatrist Henry Maudsley's pessimistic views on hereditary madness, and contemporary writing on child suicide. The book, in other cases, turns to more familiar terrain to explore literary constructions of the child's mind, as in the reading of The Turn of the Screw. The book also considers recapitulation theory, which drew parallels between children and animals or "savages," and the emergence of child psychology as an area of study in the work of James Sully. Like Smith's book, Shuttleworth's text demonstrates exhaustive knowledge of the sweep of nineteenth-century psychology.

In Popular Fiction and Brain Science in the Late Nineteenth-Century (2011), Anne Stiles examines late-century writers of Gothic literature and Romance who incorporated new theories of neurophysiology into their fiction. The study focuses particularly on research on the localization of brain functions, examining Paul Broca's work on language, John Hughlings Jackson's on the localization of speech, and David Ferrier's 1873 research on electrical stimulation of the cortex, which supported the localization of functions. Stiles argues that and explores why this is the case - popular Victorian fiction was a better venue for considering 
neurology than was the realist novel. She posits a "natural association" (21) between a sometimes sensationalized brain science and the hidden dangers at the heart of gothic fiction and the fantasies of the Romance, writing that "it is not coincidence that the complicated narratives, subterranean passages, and involved storylines traditionally associated with the late Victorian Gothic subtly remind us of the convoluted surfaces of the brain" (16-17). The book includes chapters on Robert Louis Stevenson's Dr. Jekyll and Mr. Hyde (1886) in relation to Victorian writing on the double brain and double consciousness; on Dracula (1997) and theories of automatism; on H. G. Wells, the mad scientist, and theories of genius; and on Grant Allen and memory. A final chapter examines the under-studied Marie Corelli and the incorporation of brain science in her occult romances. Supporting Gillian Beer's two-way traffic model of the interactions between science and literature, Stiles argues that popular fiction that incorporates neurology was not only influenced by the new science, but also itself "often influenced the direction of future neurological research" (1).

Stiles's book is at its strongest in its accounts of the neurological science and in drawing out connections between the fiction and brain science. The requirement that interdisciplinary work involves expert knowledge of several areas is a tall order, and Stile's book, her first one, is sometimes unclear on theories of consciousness and their implications. As someone mildly obsessed with Grant Allen, I was disappointed to see Stiles suggesting that Allen was an extreme automatist: "Allen went further than Descartes, emphasizing that even human emotion and intellectual activity amounted to no more than the creaking of a rusty wheel" (86). Allen is characterized as an automatist of the sort previously introduced in discussions of Thomas Huxley and Shadworth Hodgson. (The latter two supported the conscious automaton theory, which regarded consciousness as epiphenomenal, having no efficacy whatsoever, and Huxley famously extended the view from Descartes' account of animals as automata to humans, who are also conceived of as automata, albeit conscious ones.) Allen, however, characterized himself in one of his articles in the psychological/philosophical journal Mind as "so thorough-going a 'double-aspect partisan' that I refuse entirely to disassociate the two aspects [the mental and the physical]" and claimed, "We say truly that we saw the fruit, that we liked it, that we willed to eat it, and that the act of willing resulted in the eating" (Pain and Death" 207). He was an ardent supporter of a neo-Lamarckian view on the inheritance of acquired characteristics, a view (not unlike Samuel Butler's) in which volition matters. Thus Stiles has it wrong when she argues that Allen's automatist view is undercut by his representations of deep psychology in his fiction; first, because Allen did not deny or diminish subjective experience and, second, because even the most radical of epiphenomenalists admits the experience of consciousness. The problem posed is rather: why does consciousness exist and what does it do? Stiles also describes Allen as a supporter of brain localization: "By aligning himself with localizations, Allen demonstrated his progressive thinking on brain function" (97). And yet in his article "A Thinking Machine" (1886), which Stiles uses to maintain he was an automatist, Allen explicitly rejects the idea of brain localization, insisting: "It is the brain as a whole that thinks, and feels, and desires, and imagines, just as it is the body as a whole that walks, and swings, and digs, and dances. To locate the faculty of language, say, in a particular convolution of a particular hemisphere is almost as absurd, as it seems to me, as to locate, say, the faculty of writing in the last joint of the forefinger" (41).

Gregory Tate's The Poet's Mind (2012) examines connections between nineteenthcentury psychology and Victorian poetry, a topic that has previously been treated in a monograph only in Ekbert Faas's 1989 study on psychiatry and Victorian poetry, Retreat 
into the Mind: Victorian Poetry and the Rise of Psychiatry. Tate's book usefully extends the discussion beyond the relations between the sciences of the mind and Victorian fiction where a good part of the critical attention has so far focussed. Tate concludes that Victorian poetry was "more overtly psychological than that of previous generations, because the Victorians on the whole were more willing to engage with scientific and analytical conceptions of the self" (186). Considering the poetry of Robert Browning, Alfred Tennyson, George Eliot, Matthew Arnold, and Arthur Hugh Clough, Tate looks at the poets' uses of scientific psychology, contending that "physiological models of the mind are a crucial context within which to view Victorian poetry's representations of psychological processes" (6). Whether in agreement or in conflict with scientific psychology, Tate asserts, the poets came under its influence. That influence manifested itself in "the self analytic internal dialogue, which characterizes much Victorian poetry" [27]) and in the poets' concern with the ontology of the mind. Discussing the broad shift in the nineteenth-century from a belief in the soul to an increasing acceptance of physical accounts of the mind, Tate argues that many of the poems he considers stage arguments - in both content and form - between the immaterial soul and the embodied mind. Tennyson, he contends, wants to assert the reality of an immaterial soul, but that intent is subverted by his use of language related to the embodied mind and his recognition of the disunity of consciousness: spiritualist contentions are undercut by materialist frameworks.

It is a well-researched and wide-ranging study, which left me with this question: were the poets engaging with Victorian psychology per se or were they at times responding to the same long-standing questions about mind that fed into that psychology? If we take speculation on the nature of the mind produced during the period as constituting Victorian psychology, then the poets are engaging with nineteenth-century psychology. It makes sense that the interest in topics on consciousness and psychology, pervasive in the periodicals, would engage poets as well as novelists. But how frequently did the poets make "conceptual and terminological allusions to specific psychological theories" (5)? Discussion of the interaction between body and mind - often understood as an immaterial soul - had been pervasive in philosophy and the sciences at least since Descartes. Eighteenth-century authors exhibited an interest in neurophysiological, medical, and physiological perspectives on the mind, while sometimes contending that the dependency of mind on body did not require rejecting an immaterial soul. Tate reads Tennyson's poem "The Two Voices" (published 1842 but written 183334 ) in connection with Henry Holland's and Arthur Wigan's 1840s psychological theories of the double brain and hemispheric dissociation. It is an interesting reading, and given that the phrenologist Gall had stressed the duality of the brain at the end of the previous century, as Anne Harrington shows in her superb study, Tennyson does not necessarily need to be regarded as "anticipat[ing] later scientific theorizations of the double brain" (49), but instead as engaging theories that were already circulating. What in particular, however, makes Tennyson's dialogue an interaction with contemporary psychological theory rather than a consideration of centuries old discussion of the divided will and internal conflicts of character, subjects found, for instance, in Plato's Republic (c. 380 BC) or Augustine's Soliloquies (386 $\mathrm{AD})$ ? My question is not intended as a critique of the book, but rather as a consideration for all of us with an interest in this field: what constitutes Victorian psychology, as a distinct area of study?

As McCorristine's book shows, the concerns of nineteenth-century psychology went beyond the conventional boundaries of orthodox science, extending to examination of unusual mental phenomena and powers of mind not available in a normal waking state. 
The exceptional literary study on late-Victorian psychical research is Roger Luckhurst's The Invention of Telepathy (2002). Luckhurst's wide ranging and knowledgeable book explores "telepathy" (a term coined in 1882 and replacing earlier ones such as "thought reader") and the multiple sites of its emergence, study, and influence. Writing in a Science and Technology Studies context, and particularly adopting a Latourian ethnographic approach, which seeks to understand the heterogeneous elements (actor networks) mobilized in the construction of scientific knowledge, Luckhurst traces "the discursive constellations through which telepathy becomes an object of knowledge" (11). The book examines the aspects of psychology that focussed, in the context of the growing authority of naturalist science, on phenomena that might seem to entail the assertion of occult powers of mind: thought and affect transference, clairvoyance, trance speech, mental influence at a distance, and spirit communication, those mental abilities that would later fall under the heading parapsychology. Drawing on a wide range of sources and looking at diverse locations - including work in neurology and physics, emerging technologies, the psychological laboratory, imperialist discourse, popular journalism, and literary texts - Luckhurst demonstrates that the prospect of minds connecting beyond individuals and across distances fascinated fin de siècle thinkers. In so doing, the book takes up late-Victorian disciplinary formation; contests over epistemic authority and the boundaries of legitimate science, and confrontations between materialist and non-materialist views of mind. Many of the Victorian writers he examines sought to treat psychic phenomenon scientifically, offering theories that could explain extraordinary mental powers by appealing to yet undiscovered psychic forces connected to electromagnetism, brain waves, or Röntgen rays. Psychical researchers worked to make their subject a legitimate arena in the sciences of the mind, hoping to provide a fuller and expanded conception of the mental. Some worked within naturalist frameworks. Others resisted entirely materialist conceptions and a psychology that fully located mind in physiology, seeking to use empirical methods to establish that - as the hopeful Alfred Wallace put it - there can be "mind without brain" (In My Life 336), that is, that mind independent from the body is a reality.

In the mid-1880s, Luckhurst shows, psychology replaced the physical sciences as the central site for scientific research into telepathy and other psychical powers, and turned its attention to dream and trance states, delirium, unconscious mental operations, and cases of double consciousness. Luckhurst examines the Society for Psychical Research (also explored in Pamela Thurschwell's Literature, Technology, and Magical Thinking, 1880-1920 [2001]) and looks closely at SPR founder Frederick Myers's positing of a "subliminal consciousness" that gives mind powers that science had yet to recognize. Myers's work challenged the conception of mental unity and reimagined unconscious and abnormal mental states as evolutionary advancements, rather than as primitive recurrences or signs of degeneration. The later chapters of the book consider literary texts representing or incorporating the logic of telepathic communications, particularly gothic fiction and New Woman writing. A final chapter extends into Modernist literature and Freud's theories of psychoanalysis, connecting telepathy to the concept of transference.

Hilary Grimes' more recent study The Late Victorian Gothic: Mental Sciences, the Uncanny, and Scenes of Writing (2011) builds on the terrain explored by Luckhurst. Grimes' key contention is that "writers and mental scientists at the fin de siècle were deeply conflicted between a desire to police the boundaries of science, identity, and the mind, and, conversely, to experience the obscure thrills of the "Unknown"' (1). The book looks at the relations between the Victorian Gothic, new technologies, and the mental sciences, showing that writers drew 
on the mental sciences and experiments on the occult, especially those connected to writing. Grimes reads the ghost fiction of little-studied women writers such as Charlotte Riddell and Mary Lousia Moleworth, and considers Vernon Lee's aesthetics in relation to her supernatural tales.

As these critical and historical texts demonstrate, the new sciences of the mind entered into literary representation, high and popular, and into every aspect of the culture. William James's words on the late nineteenth-century psychological scene seem equally fitting to describe the current scholarly work on nineteenth-century psychology: "The menagerie and the madhouse, the nursery, the prison, and the hospital have been made to deliver up their material. The world of mind is shown as something infinitely more complex than was suspected; and whatever beauties it still may possess, it has lost at any rate the beauty of academic neatness" ("Frederick Meyers" 381). Perhaps the current untidy academic interest in the nineteenth-century's messy concern with the sciences of the mind suggests that, in turning to psychology's past, we recognize both the need to re-examine ideas that have come to look inevitable at present and also find mirrored in the Victorians our own fascination with brain and mind. The questions about the mind that absorbed Victorian thinkers continue to be of intense interest today in the larger culture: the relations between minds and machines, questions of volition and determinacy, identity in relation to brain disorders, problems of memory storage and access, cognition inaccessible to consciousness, the neuro correlates of cognitive processes, and, most persistently, the explanatory gap between brain and consciousness. To quote James again: "That brains should give rise to a knowing consciousness at all, this is the one mystery that returns" (Principles 1, 677).

\section{University of British Columbia}

\section{WORKS CITED}

Allen, Grant. "Pain and Death." Mind: A Quarterly Review of Psychology and Philosophy 18 (Apr. 1880): 201-16.

Allen, Grant. “A Thinking Machine.” Gentleman's Magazine 260 (Jan. 1886): 30-41.

Clarke, Edwin, and L. S. Jacyna. Nineteenth-Century Origins of Neuroscientific Concepts. Berkeley: U of California P, 1987.

Castle, Terry. The Female Thermometer: Eighteenth-Century Culture and the Invention of the Uncanny. New York: Oxford UP, 1995.

Dames, Nicholas. The Physiology of the Novel: Reading, Neural Science, and the Form of Victorian Fiction. Oxford: Oxford UP, 2007.

Danziger, Kurt. Naming the Mind: How Psychology Found Its Language. London: Sage, 1997.

Davis, Michael. George Eliot and Nineteenth-Century Psychology: Exploring the Unmapped Country. Aldershot: Ashgate, 2006.

Eigen, Joel Peter. Mad-Doctors in the Dock: Defending the Diagnosis 1760-1913. Baltimore: Johns Hopkins UP, 2016.

Eigen, Joel Peter. Unconscious Crime: Mental Absence and Criminal Responsibility in Victorian London. Baltimore: Johns Hopkins UP, 2003.

Faas, Ekbert. Retreat Into the Mind: Victorian Poetry and the Rise of Psychiatry. Princeton: Princeton UP, 1988.

Greenslade, William. Degeneration, Culture, and the Novel: 1880-1940. Cambridge: Cambridge UP, 1994. 
Grimes, Hilary. The Late Victorian Gothic: Mental Science, the Uncanny, and Scenes of Writing. Aldershot: Ashgate, 2011.

Hacking, Ian. Rewriting the Soul: Multiple Personality and the Sciences of Memory. Princeton: Princeton UP, 1995.

Harrington, Anne. Medicine, Mind, and the Double Brain: A Study in Nineteenth-Century Thought. Princeton: Princeton UP, 1987.

James, William. "Frederic Myers's Service to Psychology." Popular Science Monthly 59 (Aug. 1901): 38089.

James, William. The Principles of Psychology. Vol 1. New York: Henry Holt, 1890.

Kearns, Michael S. Metaphors of Mind in Fiction and Psychology. Lexington: UP of Kentucky, 1987.

Keen, Suzanne. Thomas Hardy's Brains: Psychology, Neurology, and Hardy's Imagination. Columbus: Ohio State UP, 2014.

Luckhurst, Roger. The Invention of Telepathy: 1870-1901. Oxford: Oxford UP, 2001.

Matus, Jill. Shock, Memory and the Unconscious in Victorian Fiction. Cambridge: Cambridge UP, 2009.

McCorristine, Shane. Spectres of the Self: Thinking About Ghosts and Ghost-Seeing in England, 1750-1920. Cambridge: Cambridge UP, 2010.

Neill, Anna. Primitive Minds: Evolution and Spiritual Experience in the Victorian Novel. Columbus: Ohio State UP, 2013.

Old Bailey Proceedings Online. www.oldbaileyonline.org.

Oppenheim, Janet. The Other World: Spiritualism and Psychical Research in England 1850-1914. Cambridge: Cambridge UP, 1985.

Owen, Alex. The Darkened Room: Women, Power, and Spiritualism in Late Nineteenth-Century England. London: Virago, 1989.

Owen, Alex. The Place of Enchantment: British Occultism and the Culture of the Modern. Chicago: Chicago UP, 2004.

Pick, Daniel. Faces of Degeneration: A European Disorder c. 1848-c. 1918. Cambridge: Cambridge UP, 1989.

Richards, Robert J. Darwin and the Emergence of Evolutionary Theories of Mind and Behavior. Chicago: Chicago UP, 1987.

Rothfield, Lawrence. "Review of In the Secret Theatre of Home: Wilkie Collins, Sensation Narrative, and Nineteenth-Century Psychology by Jenny Bourne Taylor." Modern Philology 88.1 (Aug. 1990): 97-100.

Rylance, Rick. Victorian Psychology and British Culture: 1850-1880. Oxford: Oxford UP, 2000.

Seth, Andrew. "The New Psychology and Automatism." The Contemporary Review 63 (Apr. 1893): 555-74.

Shuttleworth, Sally. Charlotte Brontë and Victorian Psychology. Cambridge: Cambridge UP, 1996.

Shuttleworth, Sally. George Eliot and Nineteenth-Century Science: The Make-Believe of a Beginning. Cambridge: Cambridge UP, 1984.

Shuttleworth, Sally. The Mind of the Child: Child Development in Literature, Science, and Medicine 18301900. Oxford: Oxford UP, 2010.

Smith, Roger. Free Will and the Human Sciences in Britain, 1870-1910. London: Pickering and Chatto, 2013.

Smith, Roger. Inhibition: History and Meaning in the Sciences of Mind and Brain. Berkeley: $\mathrm{U}$ of California $\mathrm{P}, 1992$.

Smith, Roger. Trial by Medicine: Insanity and Responsibility in Victorian Trials. Edinburgh: Edinburgh UP, 1981.

Stiles, Anne. Popular Fiction and Brain Science in the Late Nineteenth Century. Cambridge: Cambridge UP, 2012.

Tate, Gregory. The Poet's Mind: the Psychology of Victorian Poetry 1830-1870. Oxford: Oxford UP, 2012.

Taylor, Jenny Bourne. In the Secret Theatre of the Home: Wilkie Collins, Sensation Narrative, and Nineteenth-Century Psychology. London: Routledge, 1988. 
Taylor, Jenny Bourne, and Sally Shuttleworth, eds. Embodied Selves: An Anthology of Psychological Texts, 1830-1890. Oxford: Clarendon P, 2003.

Thurschwell, Patricia. Literature, Technology and Magical Thinking 1880-1920. Cambridge: Cambridge UP, 2001.

Wallace, Alfred. My Life: A Record of Events and Opinions. Vol. 2. Cambridge: Cambridge UP, 1905.

Winter, Alison. Mesmerized: Powers of Mind in Victorian Britain. Chicago: U of Chicago P, 1998.

Young, Robert. Mind, Brain and Adaptation in the Nineteenth Century: Cerebral Localization and Its Biological Context from Gall to Ferrier. New York: Oxford UP, 1990. 